\title{
Glass fins with embedded titanium inserts for the façades of the new Medical School of Montpellier
}

\author{
Jordi Torres 10 - Núria Guitart · Carles Teixidor
}

Received: 1 March 2017 / Accepted: 21 September 2017 / Published online: 31 October 2017

(C) Springer International Publishing AG 2017

\begin{abstract}
The new Medical School of Montpellier, designed by François Fontès, is enclosed by several façades stiffened by the use of glass fins up to $12.71 \mathrm{~m}$ high. The main façade assures the monumentality of the institution with its length of more than $60 \mathrm{~m}$. The façade glass panels, with a maximum size of $3.8 \times 2.8 \mathrm{~m}$, are stacked transferring the dead load to the bottom panels through plastic setting blocks. The façade panels are fixed with patch-fittings bolted to titanium inserts embedded in the vertical glass fins. The structural system is designed to resist seismic actions and to accommodate the displacement of the main structure under an earthquake scenario. The stability to lateral buckling and under seismic loads is guaranteed by a system of cables and rods which transmits the in-plane forces to the main structure. The post-breakage behaviour of the multilaminate heat-strengthened glass panels and the design of the façade guarantee the stability even under very aggressive accidental scenarios. The paper contains the main issues about the fabrication of titanium inserts laminated with SentryGlas ${ }^{\circledR}$ interlayer. The verification methodology of the glass fin with embedded titanium connections in terms of strength and stability is described. In particular, non-linear buckling analysis
\end{abstract}

J. Torres $(\bowtie) \cdot$ N. Guitart · C. Teixidor

Bellapart, Les Preses, Spain

e-mail: jtorres@bellapart.com

N. Guitart

e-mail: nguitart@bellapart.com

C. Teixidor

e-mail: cteixidor@bellapart.com and stability checks based on Eurocodes are proposed. The numerical analyses were completed with pullout tests of aged specimens in order to determine the resistance of the adhesive connections. Finally, a fullscale glass fin was submitted to a three-point bending test to validate the design including the post-breakage behaviour. A brief description of the construction phase is also included.

Keywords Façade - Structural glass component . Laminated embedded connections - Glass fin . Pull-out test $\cdot$ Full-scale tests $\cdot$ Construction

\section{Introduction}

Glass enclosures stiffened with glass fins are a solution widely used in monumental façades and skylights in order to cover large spans without the need of standard metal framing. Currently, due to the longer fabrication possibilities, it is possible to stiffen the glass outer envelope of a building by means of full height glass fins. On the other hand, the excellent structural performance of SentryGlas ${ }^{\circledR}$ ionomer interlayer enables to connect the façade to the fins by using laminated metal connections offering a very elegant solution. This connection technology was proposed just few years ago, for example (Belis et al. 2009; Louter 2009; O'Callaghan 2007; Peters et al. 2007), and is still under development. The embedded connections have been used lately in innovative façades. Probably the most iconic are the 
Apple Stores as for example (Lenk and Lancaster 2013; O’Callaghan 2012, 2007).

The design of the façades was verified according to the Eurocodes, the French construction codes and the requirements of the Centre Scientifique et Technique $d u$ Bâtiment (CSTB). Since the technique developed in this project was considered innovative and experimental, it was required the approval of the proposed solution by a committee of experts in the context of an Appréciation Technique d'Expérimentation (ATEx).

In general terms, the strategy used for the verification of the glass fins is based on the instructions defined by CSTB (Cossavella and Panait 2008). These instructions recommend dividing the verification of the glass fins in three parts. (i) Pre-dimensioning. (ii) Verification of the components or connections. (iii) Full-scale tests. The documents define the main criteria: allowable deflection, glass design resistance and safety factors to be applied in the tests.

Cossavella and Panait (2008) also proposed a method to verify the glass fins under lateral torsional buckling according to the methodology of Eurocode 3 and Eurocode 9 considering a monolithic and rectangular glass panel. The imperfection factors proposed are $\alpha_{0}=0.20$ and $\alpha_{\mathrm{LT}}=0.21$ which are equivalent to the curve (a) of Eurocode 3. This imperfection factors are based on EN 12150-1 and EN 572-2, which defines a fabrication global bending of $1 / 333$. The results according this methodology are compared to the experimental results of Luible (2004), generally showing more conservative results. Note that the normalized slenderness factor is calculated with the design strength of glass and an additional material factor of $\gamma_{\mathrm{M}}=1.1$.

Haldimann et al. (2008) proposes a similar methodology based on Eurocode 3. However, in this case, it is recommended to use the imperfection factor corresponding to curve (c) of Eurocode which is $\alpha_{0}=0.2$ and $\alpha_{\mathrm{LT}}=0.49$, as a conservative solution. Nevertheless, in this document and in Amadio and Bedon (2013a), the normalized slenderness factor is calculated with the characteristic design strength of glass $\left(\sigma_{R k}\right)$ and the material factor is $\gamma_{M}=1.0$.

Amadio and Bedon (2013a) proposed a methodology to verify monolithic and laminated glass panels under constant axial compressive forces and constant bending moments. The document calibrates the imperfection factors under constant axial compressive forces by means of available tests in the literature (Aiello et al. 2011; Feldmann and Langosch 2010; Foraboschi 2009;
Luible 2004). The imperfections factors proposed are $\alpha_{0}=0.60$ and $\alpha_{i m p}=0.71$. Based on Belis et al. (2011) the initial imperfection of thermally threated glass panels is defined to be at least L/400.

For the bending moment, in Amadio and Bedon (2013a) the imperfection factors are calibrated with numerical simulations taking into account a rotational imperfection with a maximum amplitude of $\theta=\mathrm{L} / 200 \mathrm{~h}$ (which corresponds to a mid-span deflection of L/400) the imperfection factors proposed for lateral torsional buckling are $\alpha_{0}=0.45$ and $\alpha_{\mathrm{LT}}=0.20$. Finally, the paper proposes an interaction relationship between axial loads and bending moments (Amadio and Bedon 2013a, b).

Alternatively, it is possible to verify the glass fins by means of the so-called non-linear buckling analyses with detailed numerical simulations (Haldimann et al. 2008; Luible 2004; Luible and Schärer 2016). The first eigenvector of a linear buckling analysis correctly scaled is introduced as initial imperfection to a nonlinear static analysis. The model is post-processed in order to obtain the maximum deflection and the maximum principal stress in every substep.

The embedded metal inserts in laminated glass using the excellent adhesive properties of SentryGlas ${ }^{\circledR}$ ionomer interlayer have been proposed as a promising solution by several authors (Belis et al. 2009; Lenk and Lancaster 2013; O'Callaghan 2007; Peters et al. 2007). It is possible to find examples of tests with different designs and configurations in the literature (Carvalho et al. 2011; Carvalho and Cruz 2012; Peters et al. 2007; Puller and Sobek 2012). An innovative design of a glass beam reinforced by stainless steel square hollow section laminated SentryGlas ${ }^{\circledR}$ has been included in Louter et al. (2012a, b, 2010) and Louter (2009). These papers describe the test campaign which comprises pull-out and full-size glass beam tests at several temperatures. The campaign considers long-duration loading, ageing by effects of temperature and humidity and the influence of the laminate configuration. Recently, the laminated connection with SentryGlas ${ }^{\circledR}$ has been fully characterized with the test campaign and the simulations included in the thesis (Santarsiero 2015) which results have been published in several papers (Santarsiero et al. 2016a, b; Santarsiero and Louter 2016, 2015a, 2013). The thesis contains a complete test campaign of laminated connections with SentryGlas ${ }^{\circledR}$ and TSSA ${ }^{\circledR}$ under shear and tensile loading as a function of the temperature and the strain rate. The work is com- 
pleted with detailed numerical simulations. A Generalized Triaxial Model (GTM) calibrated with the tests is proposed for the strength of the adhesive connection. Finally, small samples with embedded stainless steel inserts and a full-scale prototype are tested. Finally, Hanenberg (2016) and Santarsiero and Louter (2015b) have studied the design of the laminated hybrid connections considering the effect of ageing.

In the project described in this paper, the adhesive embedded connections are designed to work only under short-term loading. To the authors' knowledge, in the literature there are only a few references about the mid-term (snow and live load) and long-term (dead load) resistance of the adhesive connection with SentryGlas ${ }^{\circledR}$. Although in the test campaign of Santarsiero et al. (2016b) and Santarsiero (2015) the load duration of the tests are not enough long to be considered as midterm loading, the results indicates clearly that the resistance of these types of connections drops for smaller strain rates. In Louter et al. (2012a) and Santarsiero and Louter (2017) creep tests are carried out to fullscale experimental prototypes, but without focusing on the long-term resistance of the adhesive connection in function of the temperature. Denonville et al. (2013) tested small metal sheets embedded in laminated glass at different temperatures under several levels of longterm loading. The tests show a large creep deformation of the embedded connection even under very low stress states and a high dependency of the temperature. Finally, thick embedded connections under longterm loading at several temperatures are currently being tested in our facilities. The test campaign is not finished; however, the first results confirm that the embedded connections under mid-term and long-term loads should be carefully designed under very low stress state and at low temperatures, for example, for interior structural elements.

This paper contains a description of the solution applied in the façades of the New Medical School of Montpellier in Sect. 2. The fabrication of the embedded connections with titanium inserts is discussed in Sect. 3. The structural verification, Sect. 4, is focused in the glass fins with embedded connections. The resistance is verified by means of a detailed model of the insert and the stability is double-checked with a nonlinear buckling analysis and a methodology based on Eurocodes. In Sect. 5, the pull-out tests of aged specimens are carried out in order to determine the resistance of the embedded connections under short-term loading.
The design of the glass fin is finally validated in the fullscale test described in Sect. 6. The construction of the façade is briefly discussed in Sect. 7 .

\section{Description of the solution}

The design described in this paper is applied to façades V00A, V00B, V01A, V01B, V02 (Fig. 1) of the new Medical School of Montpellier. The façade V00 is divided in three independent parts with an expansion joint between them. The façade panels consist of $12.12 \mathrm{~mm}$ heat-strengthened laminated glass with $1.52 \mathrm{~mm}$ PVB. The maximum size of these panels is $2700 \times 3800 \mathrm{~mm}$. The panels are out-of-plane retained by means of patch fittings in stainless steel Gr. 1.4404 and $6 \mathrm{~mm}$ thick silicone pads (Fig. 2).

The glass panels are stacked: the upper glass panels are supported by the lower ones until the ground. The vertical load is transmitted from panel to panel by $5 \mathrm{~mm}$ setting-blocks of Teflon ${ }^{\circledR}$. The façade panels were tested with a full-scale test under in-plane loading and out-of-plane wind pressure and suction following some very demanding loading cycles. However, this test is not presented here for the sake of brevity.

The façades are stiffened by means of one-piece bottom supported glass fins with a maximum height of $12.7 \mathrm{~m}$ and a width of $0.7 \mathrm{~m}$. The build-up of the glass fins is $10.10 .10 .10 \mathrm{~mm}$ heat-strengthened lowiron glass with $1.52 \mathrm{~mm}$ SentryGlas ${ }^{\circledR}$ ionomer interlayers. The patch-fittings are bolted to titanium Gr.2 inserts which are embedded in the laminate, making use of interlayer adhesion to transfer short-term forces between glass and metal. The dimensions of the inserts are $227 \times 50 \mathrm{~mm} \times 21.52 \mathrm{~mm}$ with a radius of $25 \mathrm{~mm}$. The glass fins transmit the wind load of the façade to the main structure by means of the bottom and the top brackets. The complete contact of the four plies is guarantee by means of compression-only resin pads.

The design system of the façade guarantees the stability even under very aggressive accidental scenarios. The post-breakage behaviour of the multilaminate heat-strengthened glass panels was verified by means of the full-scale tests of the façade panels and the glass fins. Notice that in case of breakage of an outer ply of the glass fin, the adhesive area of the embedded connection is reduced to the half. The capacity 


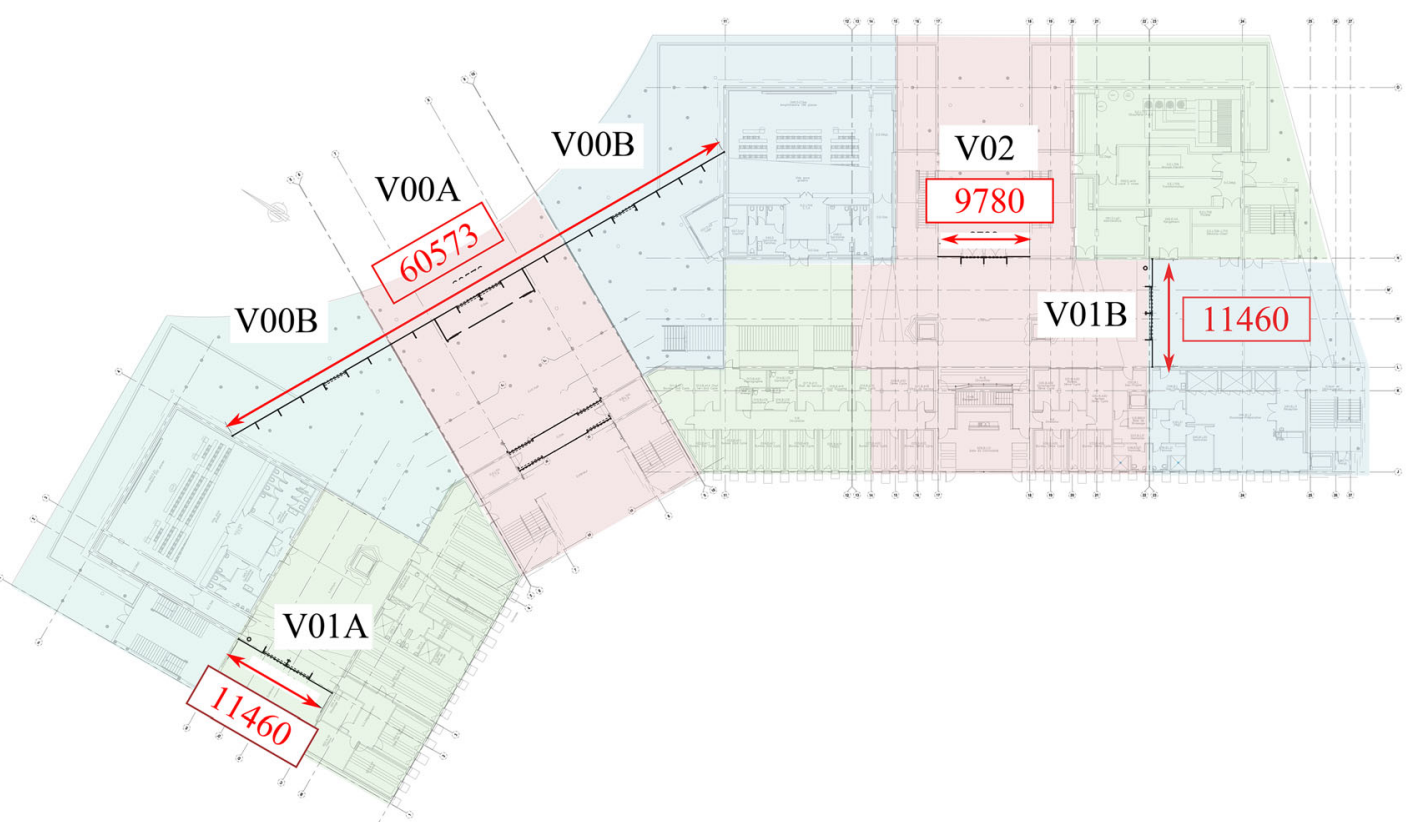

(a)

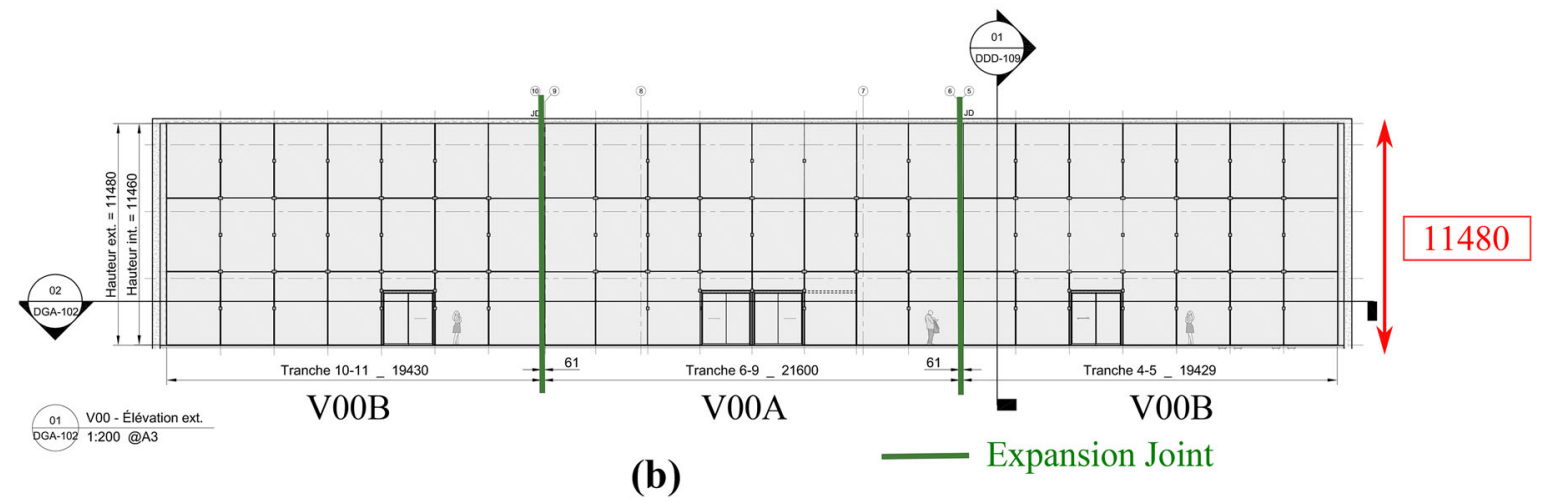

Fig. 1 a Floor plan of the building, b elevation plan of Main Façade (V00A and V00B)

of the connection to transmit the accidental wind load is verified by means of numerical simulations taken into account only the contribution of one of the outer plies. This model is not presented here for the sake of brevity.

The Medical School of Montpellier is located in a seismic zone. The seismic loads and the compatibility of deformations between the façade and the main structure were taken into account in the verification. The façade was laterally stabilized by means of a pretensioned cable system and rods which transmit the forces to the main structure. The verification under the seismic scenario is not included here for the sake of brevity.

\section{Fabrication of the glass fins with embedded inserts}

The adhesion between the embedded metal connections and glass depends strongly on the fabrication tolerances. The thickness of every panel was measured by the glass supplier. Every titanium insert was milled and polished to the corresponding thickness with a tiny tolerance. The perimetral dimensions of the inserts are constant because the recess in the inner glass panel is cut with a sufficiently accurate $\mathrm{CNC}$ process.

In spite of the tiny tolerances and the use of titanium, according to our experience, the first 5-10 $\mathrm{mm}$ of the upper/lower surfaces of the inserts could potentially 


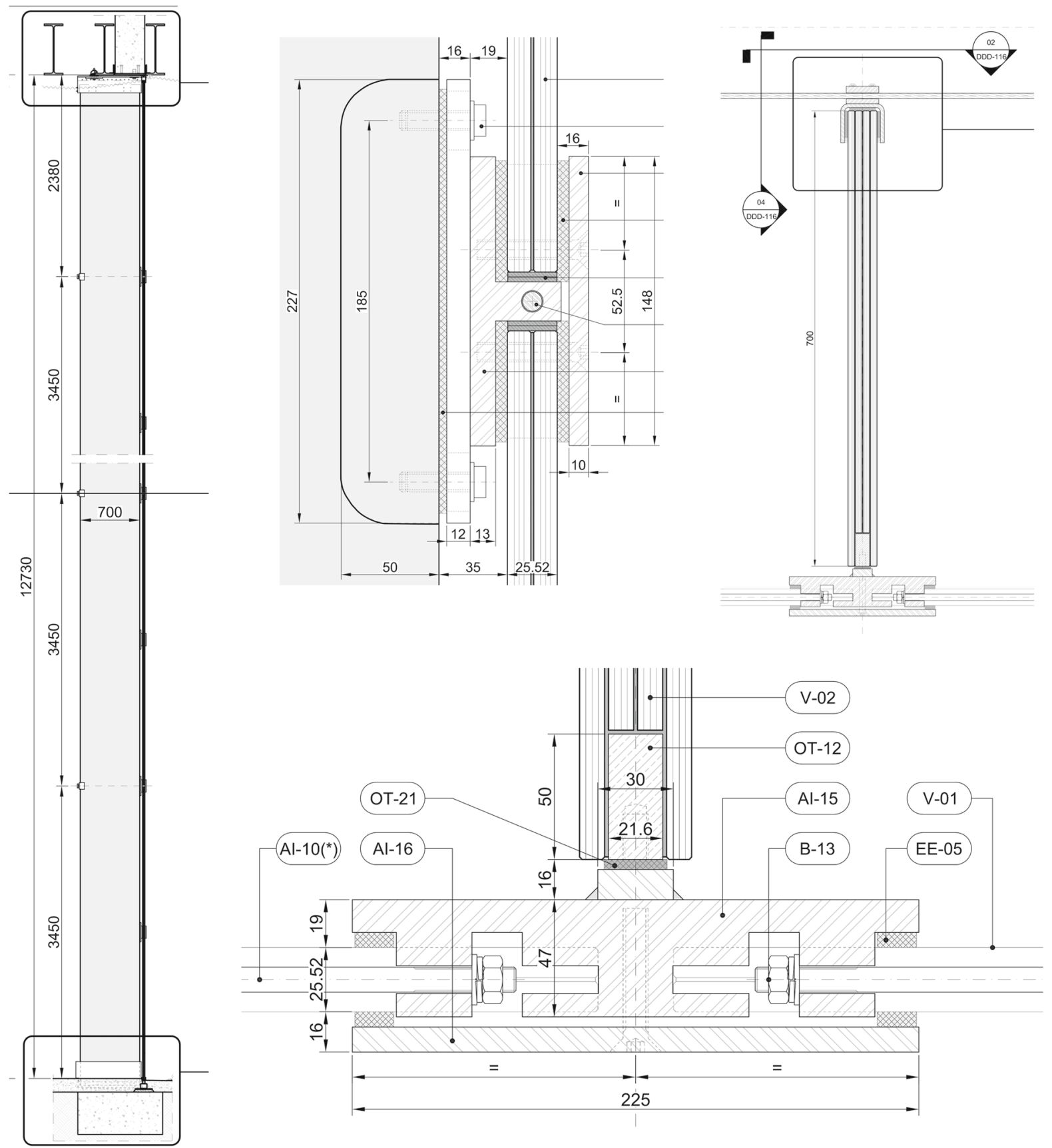

Fig. 2 Detail drawing of the façade system

show delaminations (Fig. 3). The zone more prone to delaminate is the rounded edge. Actually, the first delaminations at the round edge were observed some weeks after the glass fabrication. The lack of adhesion was observed alternatively on both interfaces; glass face or the titanium face.

For this reason, the inserts should be structurally verified assuming that the whole lateral, rounded and frontal edges are completely delaminated; a strip of 
Fig. 3 a Definitions of the part of the insert, $\mathbf{b}$ zones considered delaminated in the structural verification

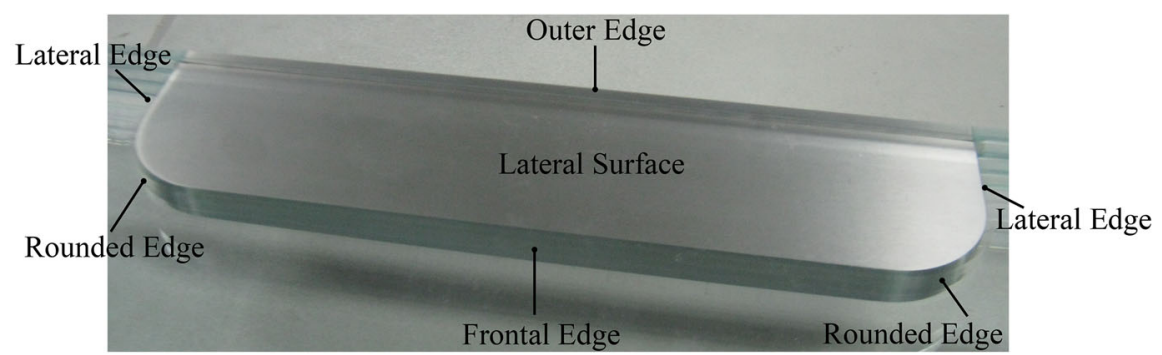

(a)

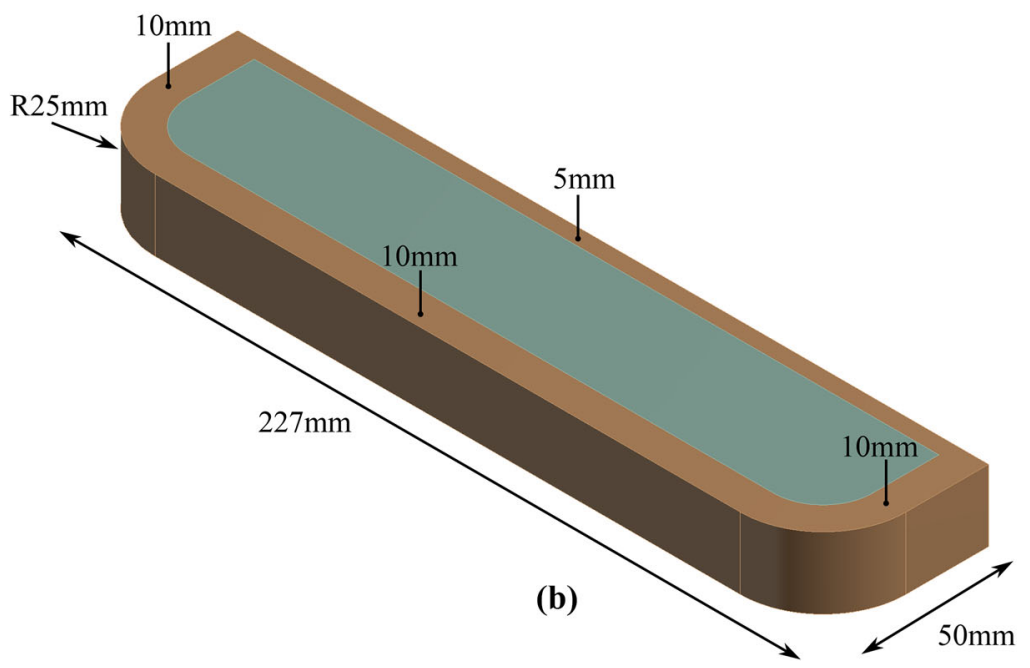

$10 \mathrm{~mm}$ along those edges on the top and bottom surfaces are also considered to be delaminated and, finally, the first $5 \mathrm{~mm}$ strip along the outer edge (Fig. 3) cannot be taken into account because it is exposed to ageing effects.

\section{Verification of the glass fins}

The glass fins were verified according to the methodology described in this section. This procedure can be extrapolated for the dimensioning and verification of glass fins with embedded metal connections in other projects. For the sake of simplicity, the additional verifications due to particularities of these façades are not included.

\subsection{Deflection check}

The deflection in Serviceability Limit State (SLS) can be verified by means of the classic beam formulas or standard engineering software. Loads were applied as concentrated forces on the embedded metal connections. In this project, the maximum allowable deflec- tion was L/300. The actual deflection was significantly smaller because it was not the governing parameter.

\subsection{Glass and laminated connection strength check}

The strength in Ultimate Limit State (ULS) was verified by means of a detailed numerical simulation. Due to the existence of the embedded connection, the stress concentrations around the notch of the inner panels are governing (Lenk and Lancaster 2013). As mentioned above, the glass fins must be verified assuming a complete delamination of the inserts along the edges and partially on the top and bottom surfaces, which in fact is a possible situation during the service life of the façade. In this scenario, the stress concentration factor could be roughly estimated by means of classical curves, for example, according to Chart 2.33 of Pilkey and Pilkey (2008) with $\mathrm{H}=700 \mathrm{~mm}, \mathrm{a}=230, \mathrm{~d}=596 \mathrm{~mm}$, $\mathrm{r}=27 \mathrm{~mm}$, the stress concentration factor would be $\mathrm{Kt} \approx 2,2$. Nevertheless, an accurate verification with numerical simulations is recommended.

The 3D volumetric model of a representative part of the glass fins with an embedded connection was mod- 
Fig. 4 Mesh details
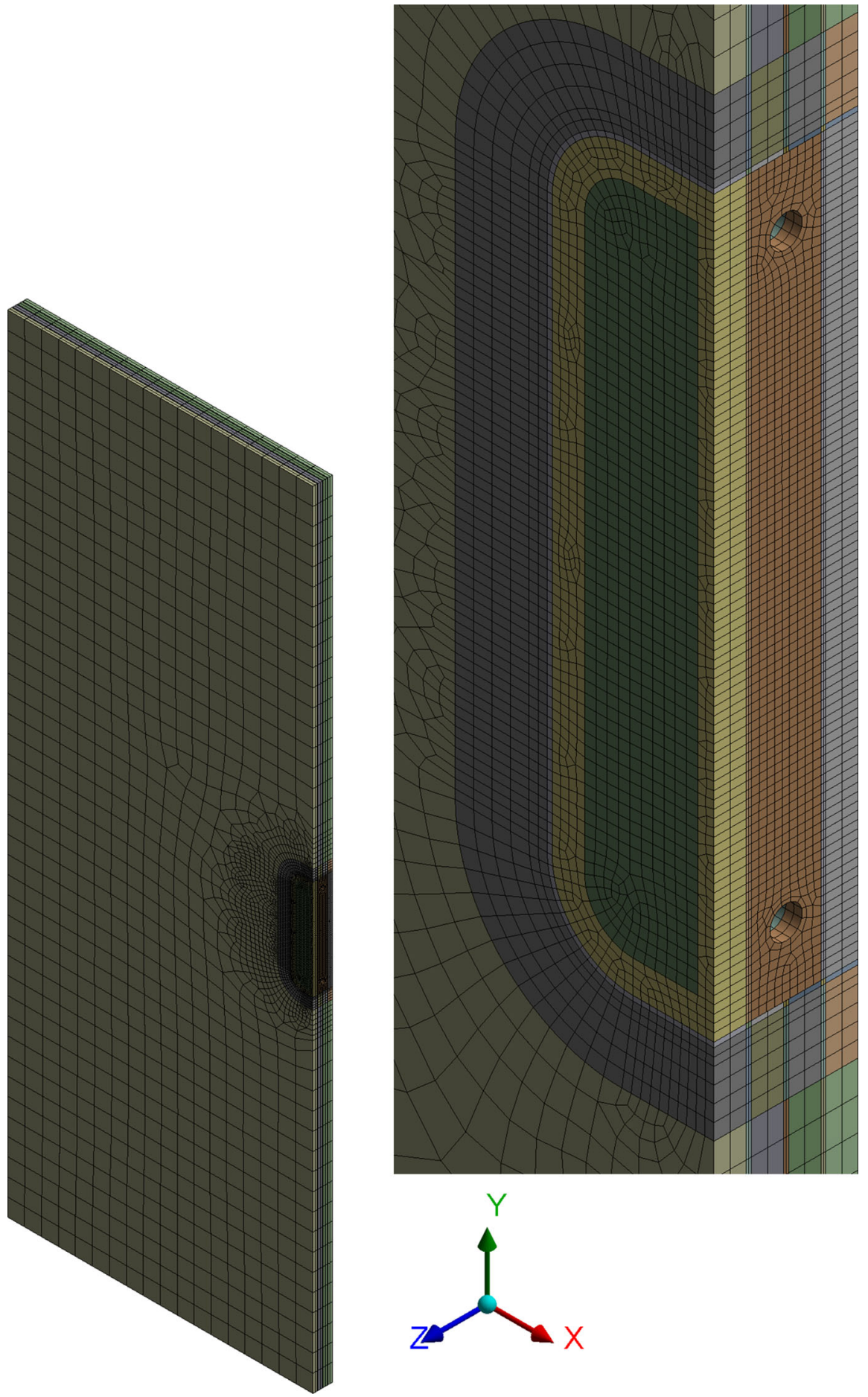

elled with ANSYS Workbench. The 20-node brick element Solid186 was used, refining the mesh around the curved edge of the insert. The criterion for validating the mesh was a difference between the nodal average stress and the element mean stress on glass under 10\% (Fig. 4). The properties of the linear isotropic elastic materials considered in the analysis were: Glass $\mathrm{E}=70,000 \mathrm{MPa} v=0.23$, Titanium Gr. $2 \mathrm{E}=$ 

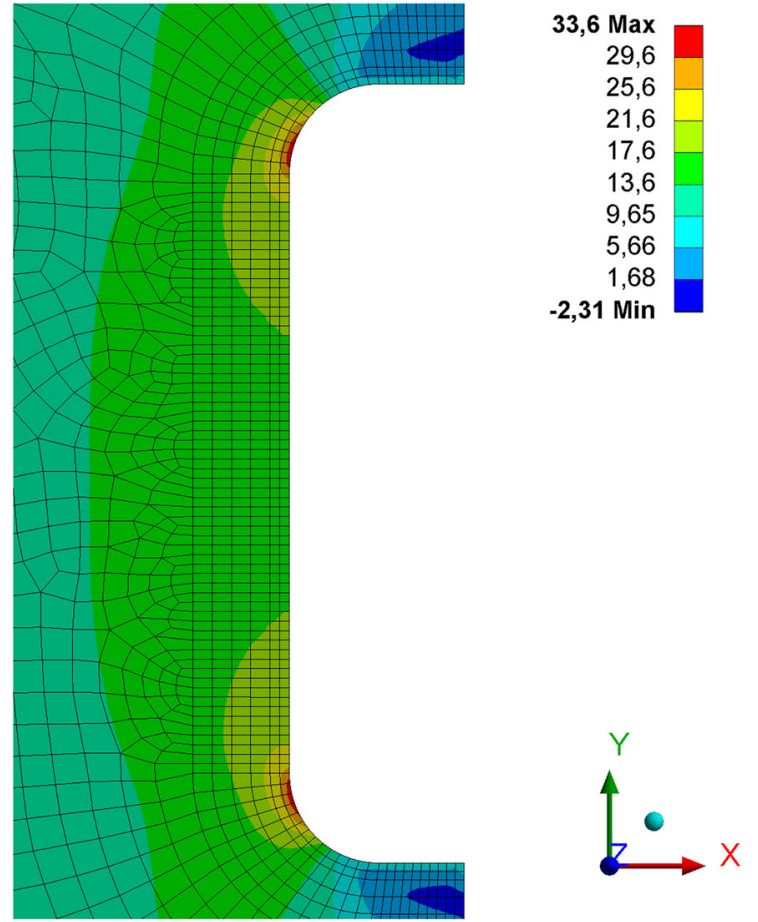

Fig. 5 Maximum principal glass stress on inner glass panels (MPa)

$103,000 \mathrm{MPa} v=0.32$, SentryGlas ${ }^{\circledR} \mathrm{E}=100 \mathrm{MPa}$ $v=0.499$, according to (DTA6/15-2253 2015). The delamination zones were modelled as Frictionless Contacts between the titanium inserts and the interlayer faces in these zones. The maximum moment due to wind load in ULS was introduced as a constant moment. The maximum concentrated force on the insert due to wind suction was considered. The analysis was considered geometrically linear (small deflection).

As expected, the maximum stress was located around the curved edge of the inner glass panels (Fig. 5), with a maximum peak stress of $\sigma_{1, \max }=33.6$ $\mathrm{MPa}$ lower than design resistance, $\mathrm{Rd}=35.0 \mathrm{MPa}$ (Cossavella and Panait 2008).

The ATEx of this project was presented September 2015 . The literature available about the verification of SentryGlas ${ }^{\circledR}$ laminated connections was largely completed in December 2015 with the test campaign included in the thesis (Santarsiero 2015) and the papers (Santarsiero et al. 2016a, b; Santarsiero and Louter 2016). The Generalized Triaxial Model (GTM) proposed by Santarsiero (2015) can be used for the strength check of the adhesive connection in numerical sim- ulations with the corresponding safety factor recommended in the Eurocodes. In the project presented in this paper, the adhesive connection was verified by means of the pull-out tests presented in Sect. 5. Notice that the pull-out tests do not take into account the stresses due to the bending moment applied to the glass fin.

\subsection{Stability check}

The stability of the glass fins was checked by means of the so-called non-linear buckling analysis. This is a non-linear static analysis where the first buckling mode is introduced as an initial imperfection (Haldimann et al. 2008; Luible 2004; Luible and Schärer 2016). The imperfection was scaled according to Cossavella and Panait (2008), but the imperfections proposed by Belis et al. (2011) and Luible (2004) could be also used. Notice that if the glass fin is bottom-supported it is necessary to take into account an additional imperfection because of the flexural buckling due to permanent loads. This analysis, which is time consuming in terms of modelling and calculation time, permits to verify that the imperfections and the tendency to buckle of the glass fins do not increase the glass stresses calculated in the strength check above acceptable limits. Note that maximum stresses are located around the inserts, which are restrained with the façade. As a consequence, the imperfections introduced do no increase the maximum principal stresses around the insert significantly. The model is not presented here for the sake of brevity.

A cross check of the stability of the glass fins was performed by means of the so-called Eurocode 3 methodology. In this case, the element is considered a monolithic rectangular glass panel with the corresponding effective thickness. The stress concentrations around inserts are not taken into account. The Eurocode methodology consists in reducing the strength of the structural element with the buckling reduction factor. For glass fins with embedded metal connections, the methodology permits to verify the resistance of the zone far from the inserts. Although Cossavella and Panait (2008) proposes a similar formulation for lateral torsional buckling with different parameters, the methodology defined by Haldimann et al. (2008) and Amadio and Bedon (2013a) is described here.

As the glass fin is bottom supported it is necessary to take into account the flexural buckling under dead load 
and the lateral torsional buckling under wind loads. The axial $\left(\mathrm{N}_{\mathrm{b}, \mathrm{Rd}}\right)$ and moment $\left(\mathrm{M}_{\mathrm{b}, \mathrm{Rd}}\right)$ design strengths are calculated as follows.

$$
\begin{aligned}
& \bar{\lambda}=\sqrt{\frac{\mathrm{A}_{e f f} \sigma_{R k}}{N_{c r}}} \\
& \phi=0.5\left[1+\alpha_{i m p}\left(\bar{\lambda}-\alpha_{0}\right)+\bar{\lambda}^{2}\right] \\
& \chi=\frac{1}{\phi+\sqrt{\phi^{2}-\bar{\lambda}^{2}}} \text { with } \chi \leq 1.0 \\
& N_{b, R d}=\chi A_{e f f} \sigma_{R D} / \gamma_{M} \\
& \bar{\lambda}_{L T}=\sqrt{\frac{W_{y, e f f} \sigma_{R k}}{M_{c r}}} \\
& \phi_{L T}=0.5\left[1+\alpha_{i m p, L T}\left(\bar{\lambda}_{L T}-\alpha_{0, L T}\right)+\bar{\lambda}_{L T}^{2}\right] \\
& \chi_{L T}=\frac{1}{\phi_{L T}+\sqrt{\phi_{L T}^{2}-\lambda_{L T}^{2}}} \text { with } \chi_{L T} \leq 1.0 \\
& M_{b, R d}=\chi_{L T} W_{y, e f f} \sigma_{R D} / \gamma_{M} \\
& \frac{N_{E D}}{N_{b, R D}}+\left(\frac{M_{E D}}{M_{b, R D}}\right)^{1 / \alpha} \leq 1
\end{aligned}
$$

where $\sigma_{R k}=70 \mathrm{MPa}$ and $\sigma_{R d}=39.3 \mathrm{MPa}$ are the characteristic and design strengths for heatstrengthened glass (PrEN16612 (Draft) 2013), $\gamma_{M}=$ 1.0 is the partial material factor (Haldimann et al. 2008), $\mathrm{A}_{\text {eff }}$ is the effective area, $\mathrm{W}_{\mathrm{y} \text {,eff }}$ is the section modulus around the strong axis (conservative), $\mathrm{N}_{\mathrm{cr}}$ and $\mathrm{M}_{\mathrm{cr}}$ are the critical axial load and the critical bending moment, $\alpha_{\text {imp }}=0.71, \alpha_{0}=0.6, \quad \alpha_{\text {imp,LT }}=0.45$ and $\alpha_{0, \mathrm{LT}}=0.2$ are the imperfection coefficients for flexural buckling and lateral torsional buckling (Amadio and Bedon 2013a, b), $\mathrm{N}_{\mathrm{Ed}}$ and $\mathrm{M}_{\mathrm{Ed}}$ are the compressive load and flexural moment in ULS and $\alpha=0.7$ is the interaction factor.

The critical buckling load is calculated with a rectangular and monolithic shell model with ANSYS Workbench 15.0 with 6-DOF, 4-node elements type shell181. The glass fin is simply supported, restraining the torsional moment at both ends. The stiffness of the cable/rod system is modelled with spring elements, $\mathrm{K}=188 \mathrm{~N} / \mathrm{mm}$. A linear buckling analysis is used to obtain the critical buckling load. The model is analyzed for two different loading conditions (Fig. 6): (i) Dead Load in ULS and (ii) Wind Load in ULS. The effective thickness is different in the two analyses. The shear transfer coefficient recommended by (DTA6/15-

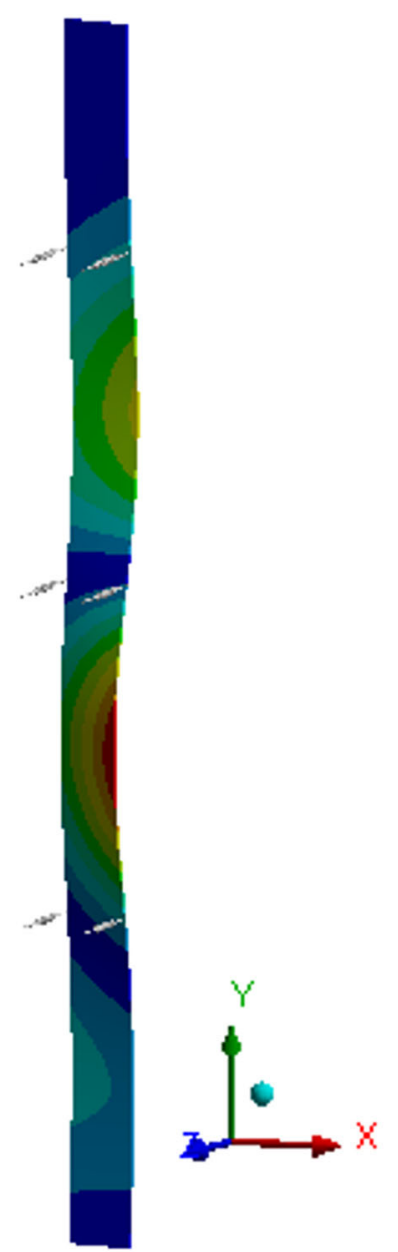

(a)

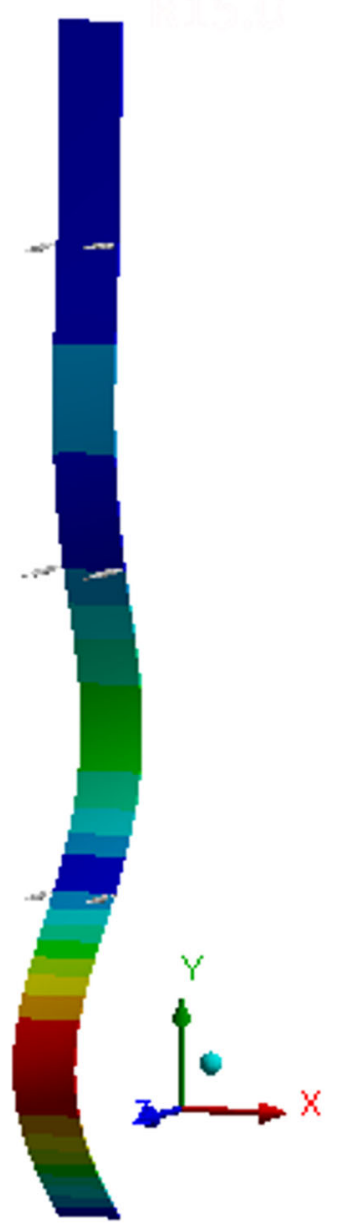

(b)
Fig. 6 First buckling modes, a flexural buckling (dead load), b lateral torsional buckling (wind load)

2253 2015) $\omega=0.7$ is used for wind load, which leads to an effective thickness of $39.09 \mathrm{~mm}$. On the other hand, the shear transfer coefficient for permanent loads recommended in (PrEN16612 (Draft) 2013) (Family 3) and (DTA6/15-2253 2015) is $\omega=0.0$. This value is extremely conservative for a SentryGlas ${ }^{\circledR}$ interlayer. For a more accurate calculation, the effective thickness can be calculated according to Galuppi and Royer-Carfagni (2014). For a $4 \times 10 \mathrm{~mm}$ laminate with $1.52 \mathrm{~mm}$ SGP, a distance of $3450 \mathrm{~mm}$ between restraints, supposing a simply supported beam with a uniform distributed load and a conservative shear stiffness of $\mathrm{G}=0.97 \mathrm{MPa}\left(60^{\circ} \mathrm{C} 10\right.$ years $)$, the effective thickness is $32.9 \mathrm{~mm}$. The critical axial load was $\mathrm{N}_{\mathrm{cr}}=\mathrm{N}_{\mathrm{Ed}} * \lambda=12.3 \mathrm{kN} * 13.76$ and the critical bend- 
Fig. 7 Photo of the pull-out test setup

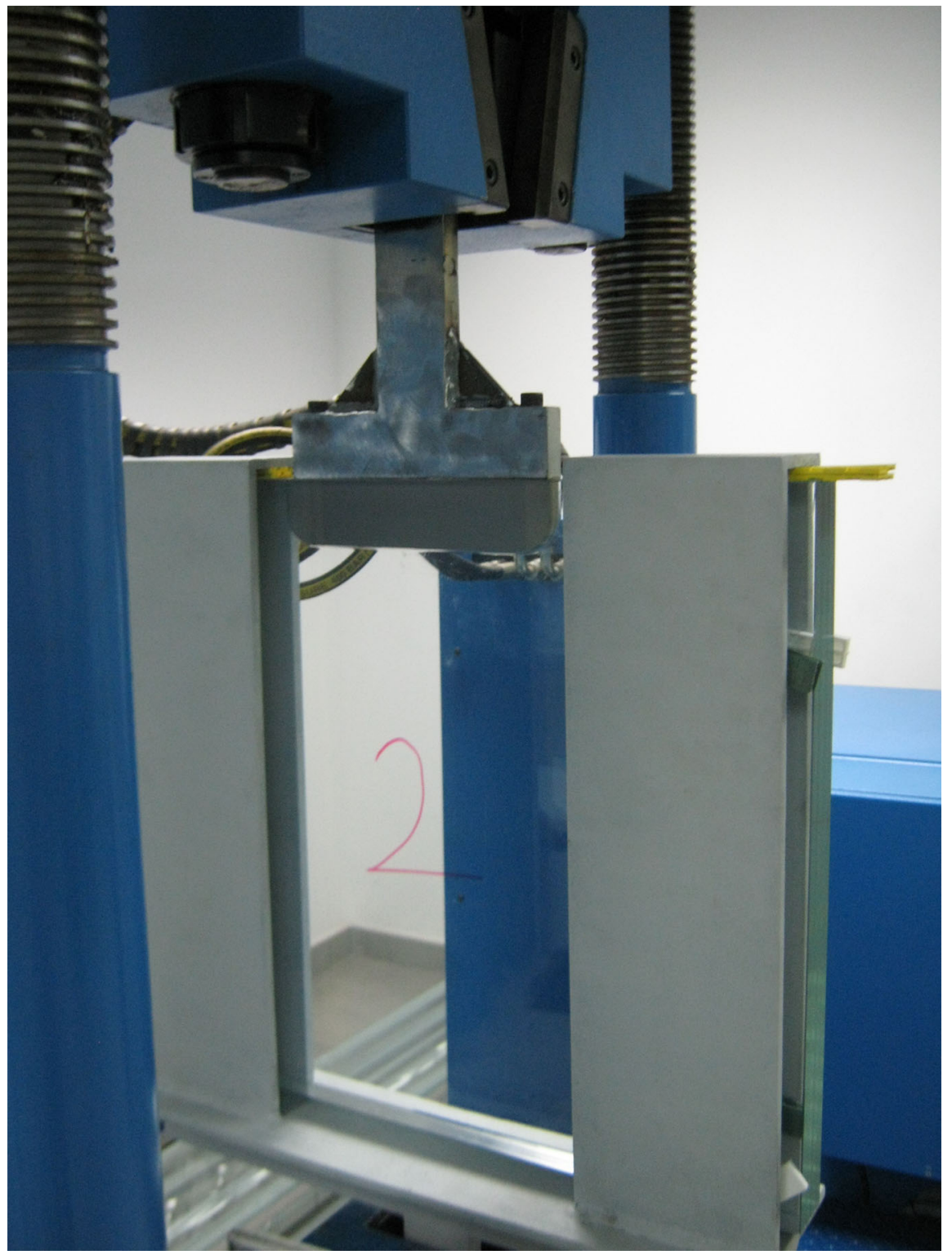

ing moment was $\mathrm{M}_{\mathrm{cr}}=\mathrm{M}_{\mathrm{Ed}} * \lambda_{\mathrm{LT}}=55.48 \mathrm{kNm} * 5.92$. For this specific glass fin, the utilization ratio was $16 \%$ for flexural buckling due to dead load and $67 \%$ for lateral buckling due to wind load. The global stability utilization ratio according to the interaction formulation was $72 \%$.

The so-called Eurocode 3 verification permits a quick stability check of the glass fins without the need of time consuming models. It is even possible to use an analytical formulation in order to determine the critical buckling load in case of simple designs of glass fins.

\section{Pull-out tests of titanium embedded connections}

\subsection{Design}

Pull-out tests of titanium embedded connections with samples of $500 \times 600 \mathrm{~mm}$ were fabricated from the same batch as the full-scale glass fins. The load was applied with an electrohydraulic universal machine with a maximum capacity of $600 \mathrm{kN}$ (Fig. 7). The displacement rate was $1 \mathrm{~mm} / \mathrm{min}$, the room temperature was $23 \pm 2{ }^{\circ} \mathrm{C}$. The test tool was made of mild 


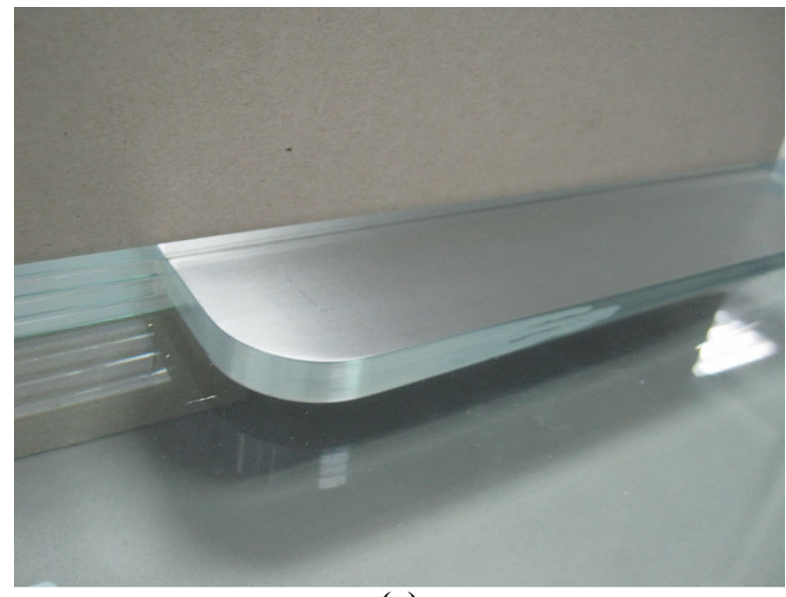

(a)

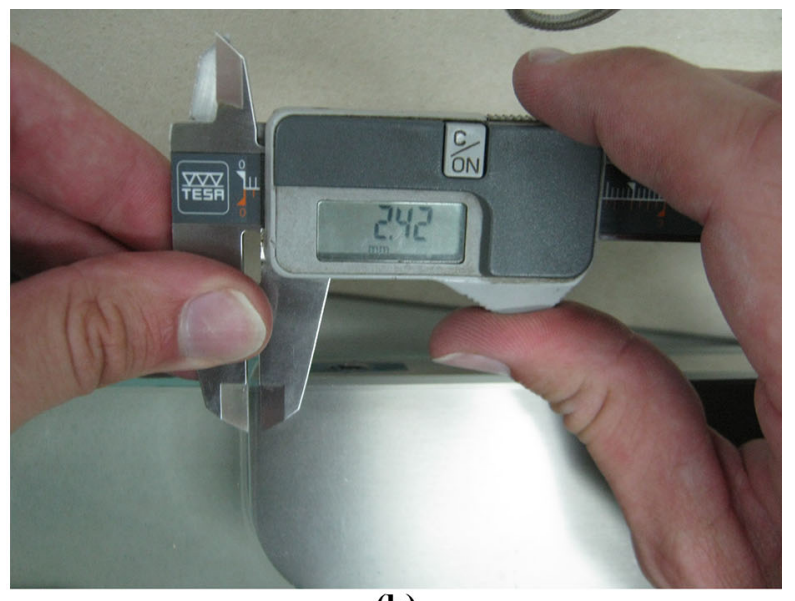

(b)

Fig. 8 Ageing of specimen no. 1: a edge delamination, b lateral surface delamination

steel grade S355 and polyethylene spacers were used to avoid direct contact between steel and glass. Bolts M10 class 12.8 were used.

\subsection{Ageing}

The specimens were aged by applying temperature and humidity cycles defined according to ISO 9142:1990 Part D. 3 but adapted to the possibilities of the climate chamber available. The cycle was $36 \mathrm{~h}$ long and consisted in (1) $15 \mathrm{~h}$ at $\mathrm{T}=40 \pm 2{ }^{\circ} \mathrm{C}$ and $75 \pm 5 \% \mathrm{HR}$, (2) $10 \mathrm{~h}$ of transition, (3) $2 \mathrm{~h}$ at $\mathrm{T}=0 \pm 3{ }^{\circ} \mathrm{C}$ and $50 \pm 5 \%$ $\mathrm{HR}$, (4) $2 \mathrm{~h}$ of transition, (5) $4 \mathrm{~h}$ at $\mathrm{T}=70 \pm 2{ }^{\circ} \mathrm{C}$ and $50 \pm 5 \% \mathrm{HR}$, (6) $3 \mathrm{~h}$ of transition. In total, the specimen was aged during $1152 \mathrm{~h}$ or 32 cycles. The chamber had some difficulties to keep the relative humidity constant at $75 \% \mathrm{HR}$, as a consequence, the humidity had peaks of $90 \% \mathrm{HR}$. During heating the humidity drops for a moment to $15-20 \%$ HR

The specimens were not aged with solar radiation because the resistance of SentryGlas ${ }^{\circledR}$ to UV radiation had been demonstrated by previous tests, for example, CTSB BV05-256 and CSTB BV05-244. Moreover, the embedded connections were installed inside the glass façade, which enclosure was composed of PVB laminated glass panels filtering at about $97 \%$ of the incident $\mathrm{UV}$ radiation.

All the specimens were intact after ageing but specimen no.1, which was partially delaminated along the edges and in a small strip of $2-2.5 \mathrm{~mm}$ at both lateral surfaces (Fig. 8). The interface delaminated was the titanium to SentryGlas ${ }^{\circledR}$. A reduction of the resistance due to this delamination was not observed in the test.

\subsection{Results}

The pull-out force versus displacement curves are shown in Fig. 9. The curves are divided in three phases. (i) Settlement Phase until approximately $1 \mathrm{~mm}$. (ii) Linear Phase: The stiffness shown in the curves corresponds to the polyethylene spacers placed between glass and steel. (ii) Plastification and failure of the bolts. Due to the high resistance of the inserts, the M10 class 12.9 bolts were broken before glass failure occurs. Due to small asymmetries in the tool or the assembly, only one of the bolts was stretched until ultimate failure. Only in two of the specimens a glass fracture occurred.

Most of the delaminations could be detected by a loud sound but they were not perceptible in terms of stiffness. The detected delaminations or the glass breakage are indicated in the Fig. 9. A summary of the pull-out tests is shown in Table 1.

All samples delaminated along the edges of the inserts. The delaminations were extended to a maximum of $2.5 \mathrm{~mm}$ on the perimeter of the top and bottom surfaces. Although, the delaminations were initiated at the titanium/SentryGlas ${ }^{\circledR}$ interface, Fig. 10, around the rounded edges, they were also present in the SentryGlas ${ }^{\circledR} /$ glass interfaces (S2, S3 and S4). In S2 and S4 the delamination jump between interfaces at the end of 
Fig. 9 Load-displacement curves of pull-out tests

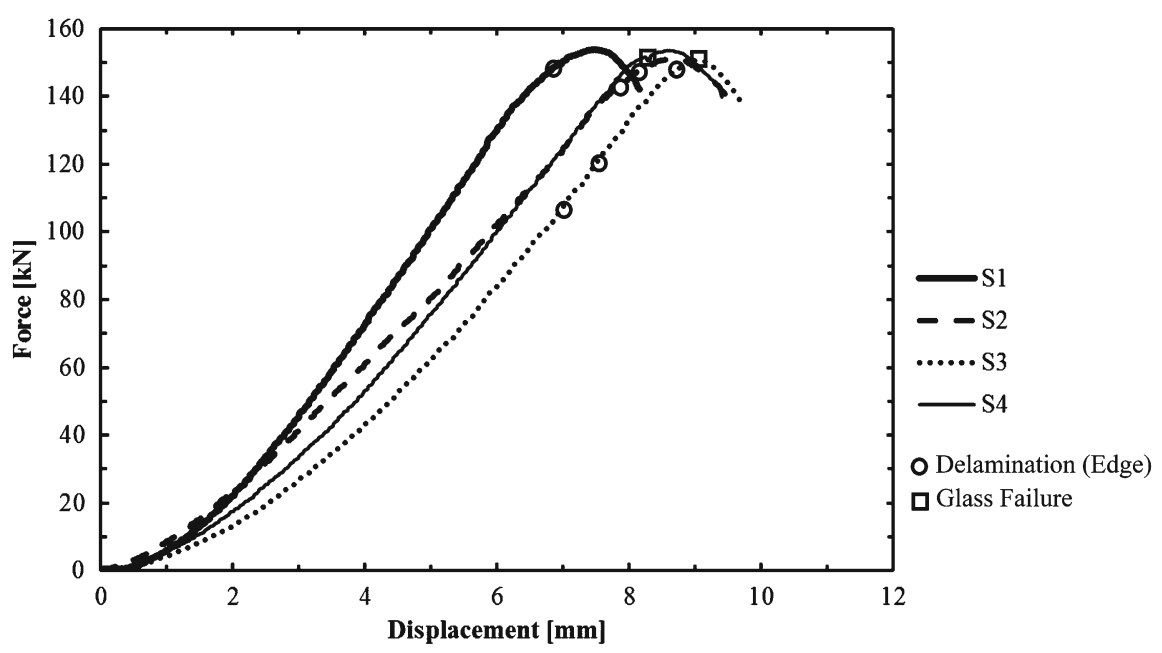

Table 1 Summary of the results of the pull-out tests

\begin{tabular}{lllll}
\hline Nos. & Load to first sound $(\mathrm{kN})$ & Damage related to first sound & Force glass failure $(\mathrm{kN})$ & Force bolt failure $(\mathrm{kN})$ \\
\hline S1 & 147 & Edge delamination & - & 153.8 \\
S2 & 144 & Edge delamination & - & 151.3 \\
S3 & 113 & Edge delamination & 150 & 150.7 \\
S4 & 151 & Glass failure & 151 & 153.5 \\
\hline
\end{tabular}

Fig. 10 Photo of the specimens after testing: a specimen 1 , b specimen 2 , c-e specimen $3, \mathbf{f}, \mathbf{g}$ specimen 4

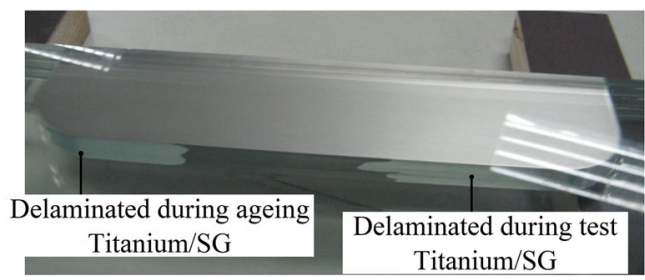

(a)

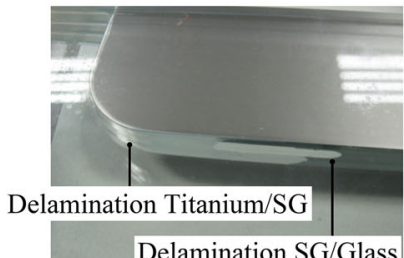

Delamination SG/Glass

(c)

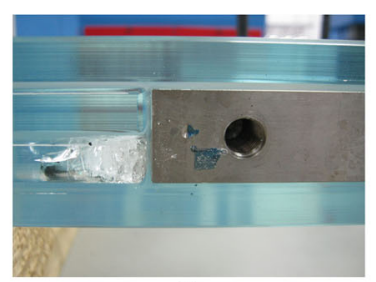

(f)

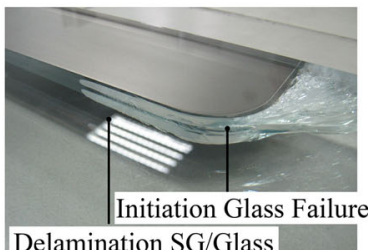

(d)

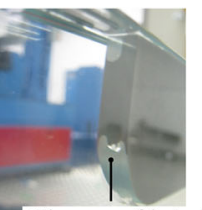

Change of interface from Titanium/SG to SG/Glass

(b)

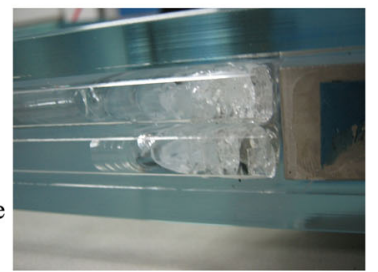

(e)

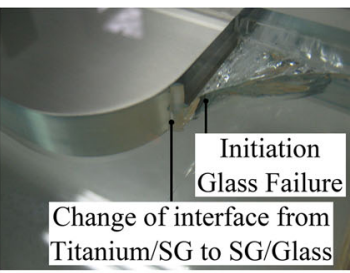

(g) 
Fig. 11 Full-scale tests of glass fins, a general setup, b horizontal displacement gauge, $\mathbf{c}$ middle span hydraulic jack, $\mathbf{d}$ axial compression hydraulic jack

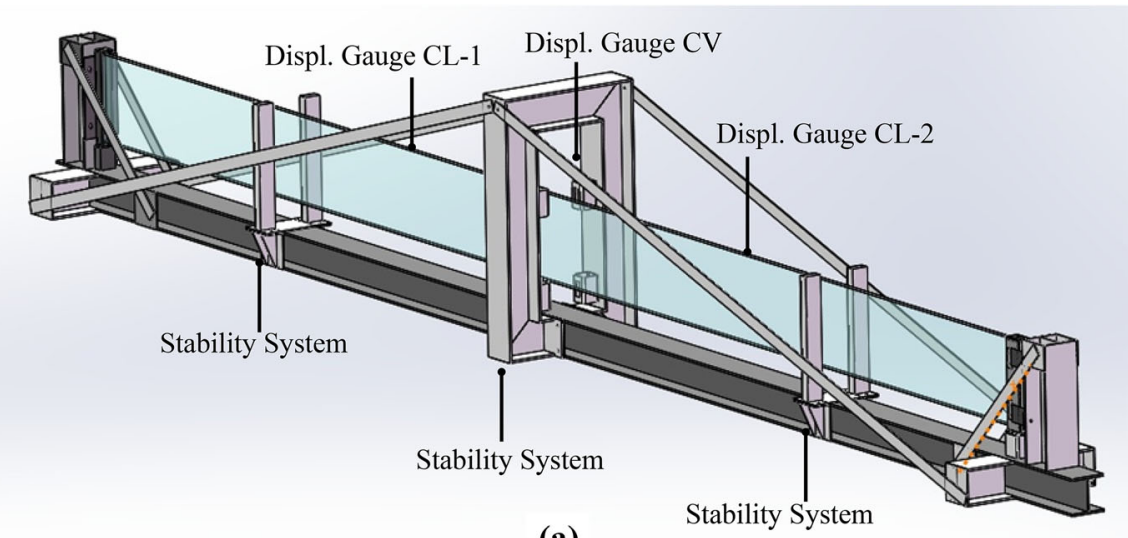

(a)

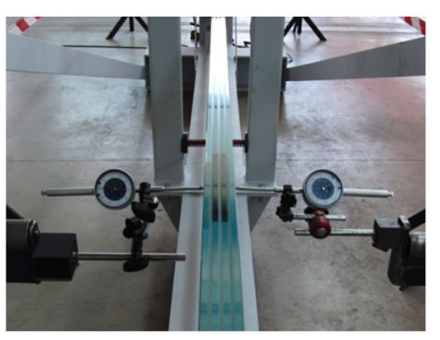

(b)

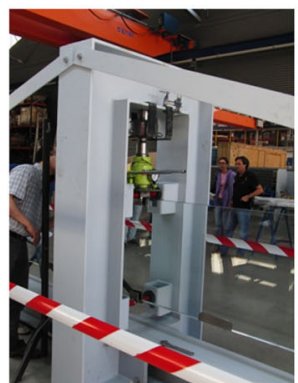

(c)

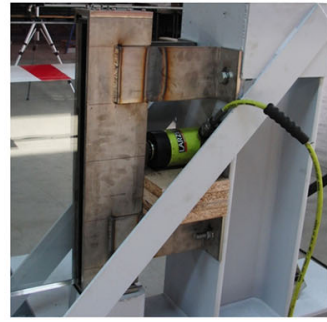

(d) the curved edges was perfectly visible (Fig. 10b, g). None of these delaminations were relevant in terms of the resistance of the embedded connection because they appeared inside the zones already considered unbonded in the numerical simulations.

In S3 and S4 the glass fracture occurred before the bolts collapse (Fig. 10d-g). The crack origin was located around the curved edge of the inner panels which were recessed to accommodate the embedded inserts. Then, the cracks followed an angle of approximately $30^{\circ}$ until the outer edge of the glass panels. This failure mode is different than the observed by Santarsiero (2015), in which the failure initiates at the outer glass panels, at the region close to the edge of the metal insert. This is because the specimen of Santarsiero (2015) had a uniform bolts distribution along the length of the insert. However, due to constructive reasons of this project, the bolted connections consisted of only 2 bolts which are close to the metal edge. Therefore, this design of bolted connection in the embedded insert does not use all the capacity of the adhesive connection. Further studies could determine which is the optimum distribution of bolts in order to maximize the insert resistance.
The results of the pull-out tests were used to calculate a pseudo-characteristic resistance of the embedded connection for this project. Although, as aforementioned, the delaminations were inside the zone where delaminations are permitted, the first perceptible sound was taken as the resistance of the sample (very conservative). The characteristic resistance was calculated according to Cahier 3574_v2, ETAG002 and NF ISO $16269-6$ as the $5 \%$ percentile ( $75 \%$ confidence) of the strength distribution: with $n=4$ then $k=2.68$. The characteristic resistance of the connection for this project was $R k=91.2 \mathrm{kN}$. The material safety factor of 2.5 was applied according to IStructE "Guide to the structural use of adhesives", 1999. Hence, the design resistance was $R d=36.8 \mathrm{kN}$, whereas the design force in ULS was only $\mathrm{F}_{\mathrm{Ed}}=6.5 \mathrm{kN}$, which is only $17 \%$ of the design resistance.

Notice that the pull-out tests were carried out at room temperature $\left(23 \pm 2{ }^{\circ} \mathrm{C}\right)$. According to the references available in the literature of embedded connections with SentryGlas ${ }^{\circledR}$ tested at different temperatures (Louter et al. 2012a, 2010; Puller et al. 2011; Puller and Sobek 2012; Santarsiero 2015; Santarsiero and Louter 2015a), there is a drop of the connection resistance 
Table 2 Summary of the full scale test

\begin{tabular}{|c|c|c|c|c|c|c|}
\hline Step & Situation & Hydraulic jack 1 (kg) & Hydraulic jack 2 (kg) & $\mathrm{CV}(\mathrm{mm})$ & CL-1B (mm) & CL-2B (mm) \\
\hline \multicolumn{7}{|l|}{ Part 1} \\
\hline 1.a & SLS & 1019 & $708 \mathrm{~kg}$ & 3.2 & 0.43 & 0.49 \\
\hline 1.b & Return to zero & - & - & -0.02 & 0.09 & 0.0 \\
\hline \multicolumn{7}{|l|}{ Part 2} \\
\hline 2.a & Initial & 0 & 0 & 0 & 0 & 0 \\
\hline 2.b & ULS & 1270 & 1300 & 6.35 & 0.51 & 0.59 \\
\hline $2 . c$ & $2 \times \mathrm{ULS}$ & 1270 & 3118 & 16.15 & 1.85 & 2.07 \\
\hline 2.d & - & 1270 & 3998 & 20.85 & 2.88 & - \\
\hline 2.e & - & 1270 & 4970 & 23.25 & - & - \\
\hline $2 . f$ & - & 1270 & 6000 & 30.25 & - & - \\
\hline $2 . \mathrm{g}$ & - & 1270 & 7000 & 36.40 & - & - \\
\hline 2.h & First failure & 1270 & 8000 & - & - & - \\
\hline $2 . \mathrm{i}$ & Just after first failure & $>2000$ & 7529 & 42.00 & - & - \\
\hline $2 . j$ & Second failure & $>2000$ & 843 & 50.45 & - & - \\
\hline \multicolumn{7}{|l|}{ Part 3} \\
\hline 3.a & Post-breakage ELU & $>2000$ & 1307 & 69.20 & - & - \\
\hline 3.b & Return to zero & $>2000$ & 21 & 25.30 & - & - \\
\hline
\end{tabular}

a maximum of $50-70 \%$ between 23 and $40^{\circ} \mathrm{C}$. The specific value in the range depends on the connection design. The reduction arrives to a maximum of $85-95 \%$ at $60{ }^{\circ} \mathrm{C}$ which is above the glass transition temperature of the SentryGlas ${ }^{\circledR}$. According to the project specifications, in the worst of the cases the maximum temperature expected on the façades taken into account the solar radiation is $41.5^{\circ} \mathrm{C}$. However, the maximum temperature expected in the glass fins is significantly lower because (1) they are considered interior elements, (2) the façades are north orientated or partially shaded by the main building, (3) for the region where the project is built, the episodes of extreme temperature do no trend to coincide with the episodes of maximum wind load (Santarsiero 2015).

\section{Full-scale tests of glass fins}

\subsection{Design}

A full-scale test was designed considering an envelope of all the façades and loading scenarios. (i) The longest glass fin was tested, $12,710 \times 700 \mathrm{~mm}$, with a distance between fixing points of $3800 \mathrm{~mm}$. (ii) It was restrained out-of-plane with industrial springs with the minimum stiffness of the cables and rods installed on site, $\mathrm{K}=$ $190 \mathrm{~N} / \mathrm{mm}$ until $0.3 * \mathrm{~L}_{0}=26.7 \mathrm{~mm}$. PTFE sheets were installed to minimize the friction force. (iii) The titanium inserts were located at the opposite side of the loaded edge, which was under tensile stress. This was a non-realistic scenario; however, it permitted to check the stability of the glass fin and the stress concentration around the inserts with only one full-scale test.

The glass supplier verified the bending strength of glass by means of 4 points bending tests according to EN 1288-3 and a fragmentation test according to EN 1863-1:2012. The bending strength of the samples was between 128.88 and $134.09 \mathrm{MPa}$, which were at the high range of the heat-strengthened glass.

\subsection{Instrumentation}

The glass fin was validated with a three-point bending test. Actually, the façade is loaded through the 5/6 inserts along the length. In order to have comparable results, the punctual force applied in the middle span of the glass fin during the test was calculated to produce the same bending moment than the real glass fin in SLS, ULS and $2 \times$ ULS. The additional moment due to grav- 


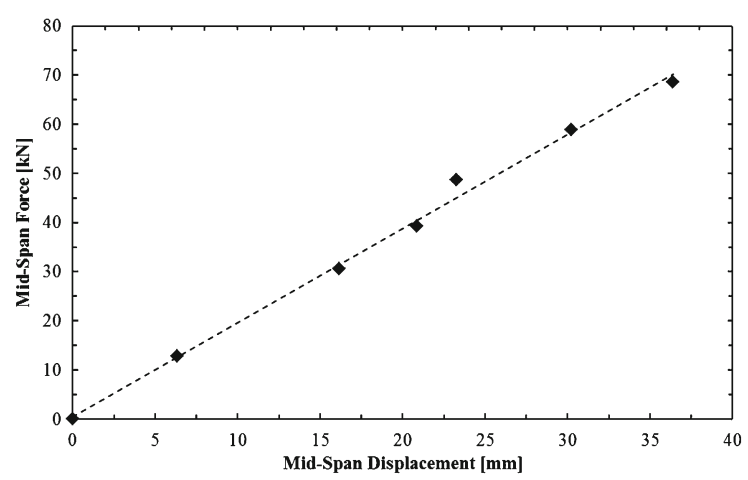

Fig. 12 Load-displacement curve of the second part of the test until first failure

ity (the specimen was tested in a horizontal arrangement) was taken into account.

The force in the middle span was introduced by means of a manual hydraulic jack and a load cell with a standard display (Fig. 11). An axial compression force simulating the dead load on site was introduced with another manual hydraulic jack and a display. The inplane displacement was captured by means one vertical displacement gauge at mid-span of the fin. Four horizontal displacement gauges were located at the midpoint of the free span between lateral fixations in order to capture the out-of-plane displacement. The test carried out with a room temperature of $23 \pm 2{ }^{\circ} \mathrm{C}$. The manual loading time was executed with discrete pulsations spaced approximately $30 \mathrm{~s}$. The lapse time in order to read and write down all force and displacement readings was approximately $30 \mathrm{~s}$, too. The testing methodology and protocols were agreed with the CSTB before the test.

\subsection{Results}

The first phase of the tests consisted in charging the glass fin until SLS loading conditions. Take into account that the deflection due to dead load was already produced before the beginning of the test. The phases of the test and the corresponding loads and displacements are shown in Table 2.

In the second phase, the glass fin was loaded progressively until the first crack appears (Fig. 12). The minimum resistance required by CSTB was twice the ULS load. The lateral indicators measured the out-ofplane displacement until this load. The glass fractured at $8000 \mathrm{~kg}$ with an in-plane displacement of approximately $42.0 \mathrm{~mm}$. The exact displacement just before the failure could not be observed, due to the $30 \mathrm{~s}$ delay in acquisition. The crack initiated around the embedded connection located near the mid-span of the glass fin (Fig. 13). Specifically, the origin of the crack was the end of the rounded edge of both inner glass panels, which coincides completely with the prediction of the numerical simulations. The failure was extended to a $2 \mathrm{~m}$ long zone. The cracks covered all the tensioned zones up to the neutral axis of the glass fin. After the first crack, the load was kept constant (DL $>2000 \mathrm{~kg}$ and $V=7529 \mathrm{~kg}$ ). After $10 \mathrm{~min}$, a second and more extensive breakage was produced because the creep of the interlayer increases progressively the stress on the glass panes. This time, the 4 panes of the laminate were broken. The cracks reached the top edge of the fins and cover an extension of $5 \mathrm{~m}$.

The resistance of the glass fin was higher than expected in the numerical simulations. This was due to several reasons: (i) The material safety factors, (ii)
Fig. 13 Photo of the glass fin after the first failure

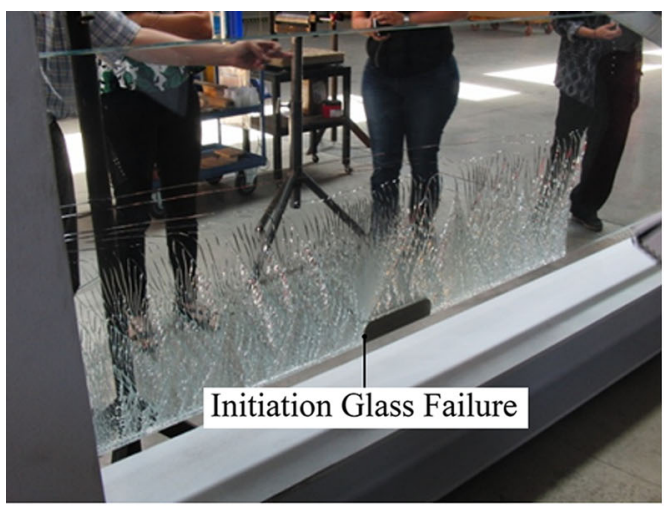

(a)

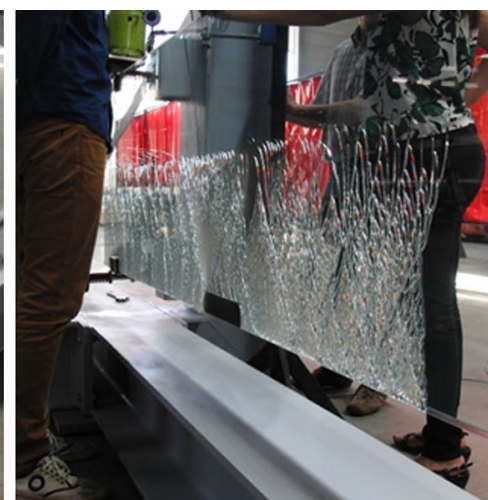

(b) 


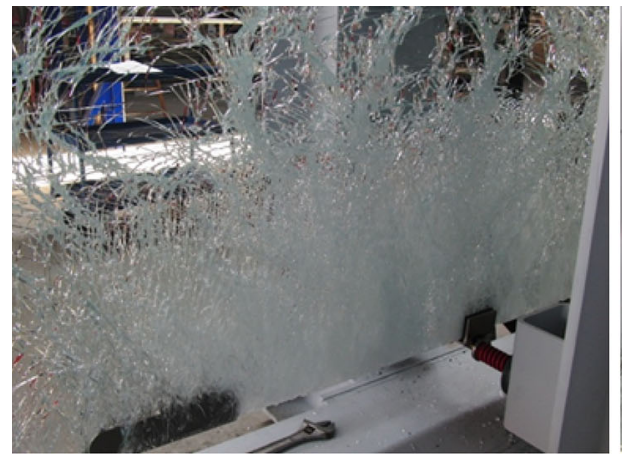

(a)

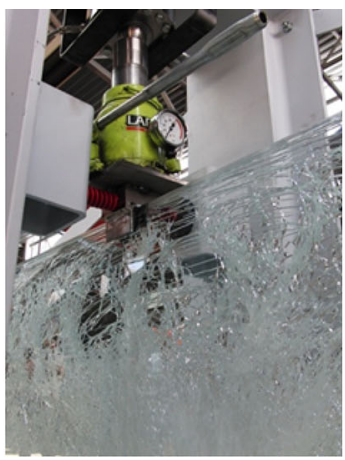

(b)

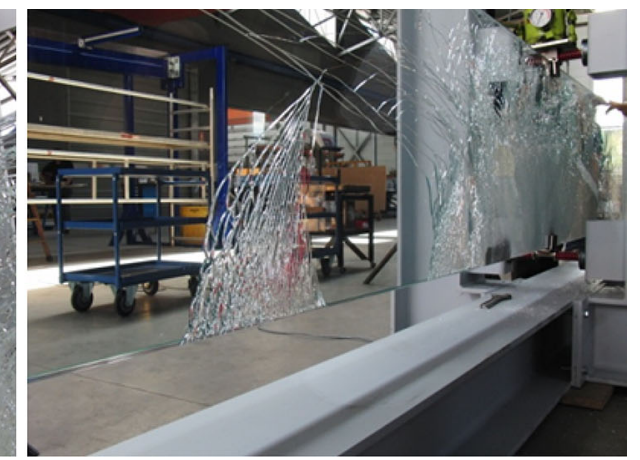

(c)

Fig. 14 Photo of the glass fin after the post-breakage test

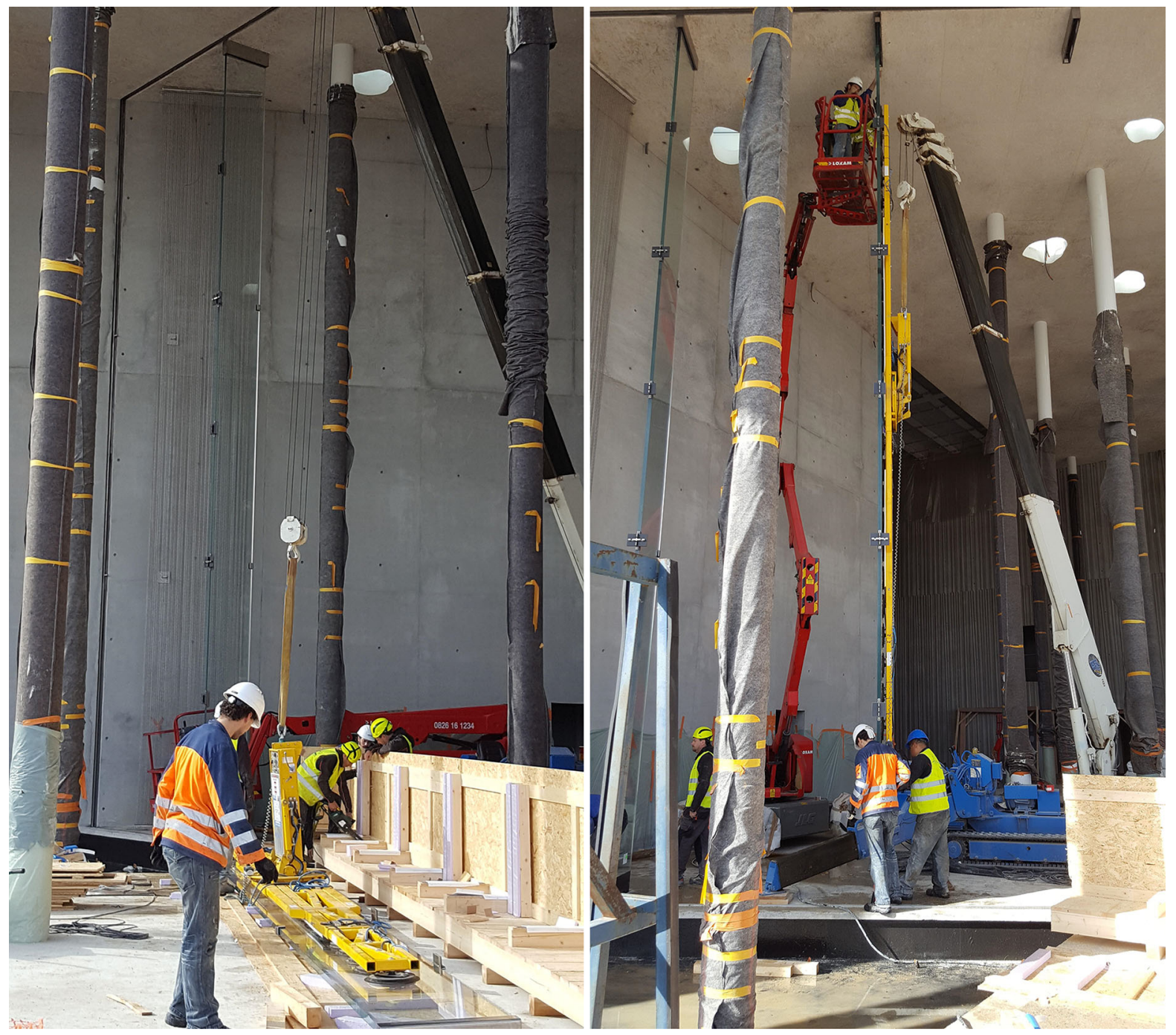

Fig. 15 Installation of the glass fins 


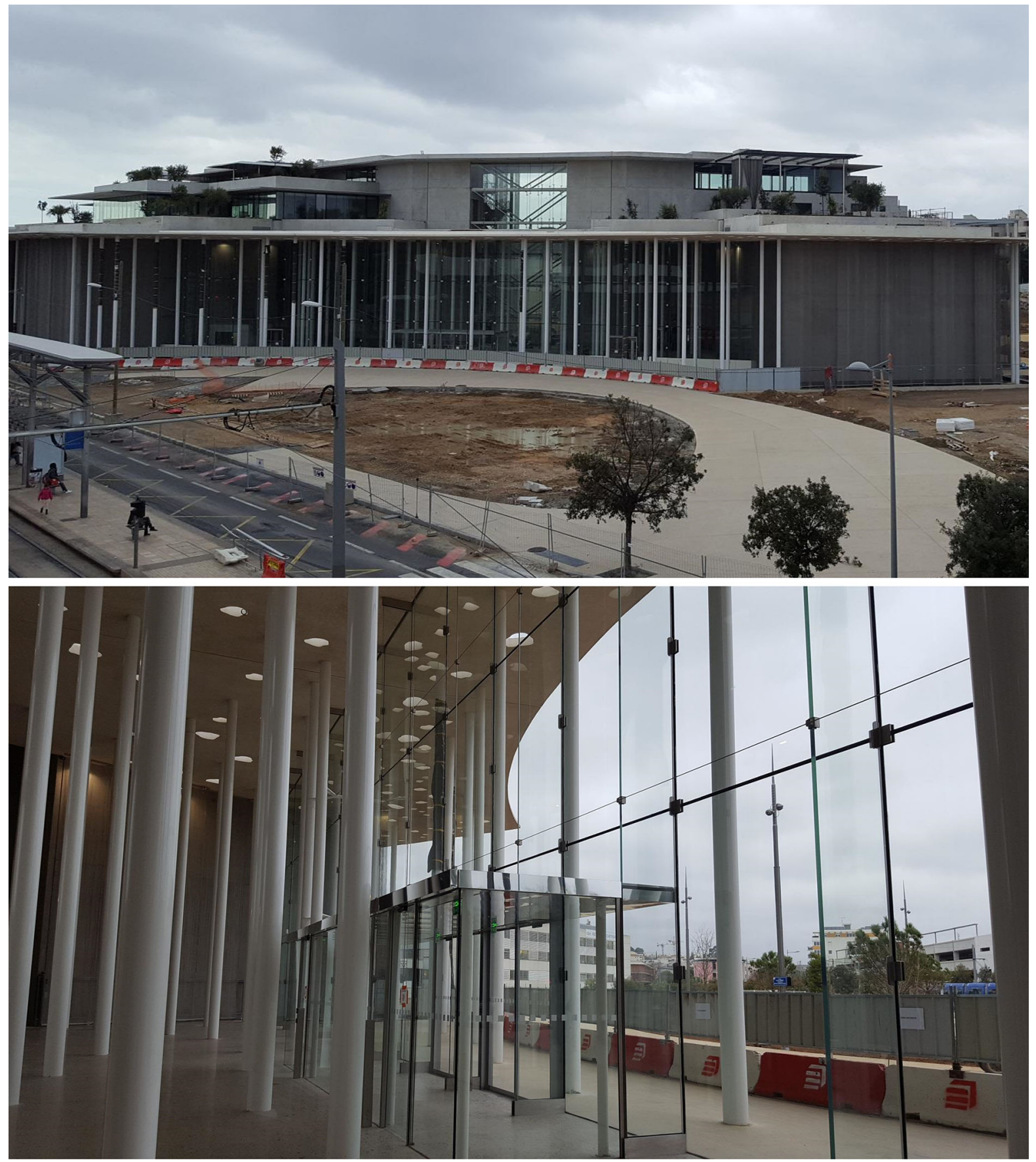

Fig. 16 Monumental Façade V00 almost finished

The surface prestress showed to be on the upper range permitted for heat-strengthened glass, (iii) the embedded connections were not delaminated, as a consequence, the stress concentration factor was lower than the one calculated in the detailed numerical simulation.

In the third part of the test, the in-plane force was increased again until ULS loading. The crack grew sig- 
nificantly but with a very good post-breakage stability without any sign of collapse (Fig. 14).

\section{Construction}

The construction of the façades of the new Medical School of Montpellier started on February 2016. After erecting the steelwork, the glass fins were installed successfully between May and November 2016, with a maximum installation rate of 4 fins per day. The glass fins were installed by using spider crane and a vacuum suction system (Fig. 15). The façades were installed sequentially, so the installation times also considered the façade panels and all the finishes. The works were finished by February 2017 (Fig. 16).

\section{Conclusions}

This work contains a description of the techniques used in the monumental façades of the New Medical School of Montpellier, designed by François Fontès. The paper is focused on the heat-strengthened glass fins with a maximum span of $12.71 \mathrm{~m}$ in a single piece, which are connected to the façade panels by means of embedded titanium inserts. The fabrication of the inserts and the permissible delamination along their perimeter are discussed. The structural verification of the detail was carried out taking into account the limitations described. The glass fins were verified in terms of strength with a detailed model of the insert zone. The governing parameter was the stress concentration at the curved edges of the inner glass panels due to the notch necessary to accommodate the insert. The glass fin stability was double-checked. First, it was verified by means of the so-called non-linear buckling analysis taking into account the imperfections which do not show a significant increase on stresses at the insert zone. Additionally, the stability checks based on Eurocodes were performed by combining the flexural buckling and the lateral torsional buckling of the glass fin. This methodology permits the stability verification without the need of time consuming models.

The numerical simulations were completed with laboratory tests. Aged specimens with embedded connections were tested in pull-out, demonstrating the high adhesive capacity of SentryGlas ${ }^{\circledR}$ at room temperature. One of the specimens showed delaminations along the edges before the tests. However, all delaminations occurring during the tests were inside the zones in which these are permitted. The characteristic resistance of the connection under tensile load was significantly higher than the design forces. Glass failure occurred around the curved edges of the inner glass panels due to the proximity of the bolted connections to these zones.

A full-scale test of a glass fin validated the design showing a resistance even higher than expected due to the glass safety factors, the superficial pre-compression in the upper range for heat-strengthened glass and the fact that during the tests the embedded inserts did not delaminate. The post-breakage stability of the glass fin was excellent, supporting even the ULS loading.

Acknowledgements The authors would like to thank François Fontès and the team of Fontès Architecture. In addition, the CSTB and SOCOTEC teams, specifically Mrs. Orand and Mr. Valem. Also, we would like to thank the glass supplier, Sedak $\mathrm{GmbH}$. Finally, the authors would like to thank the team of Bellapart: R. Brugués, L. Estupiña, P. Guerold, M. Millastre, J. F. Portal, J. Pereira and G. Robert, which have been working hard in this project.

\section{Compliance with ethical standards}

Conflict of interest On behalf of all authors, the corresponding author states that there is no conflict of interest.

\section{References}

Aiello, S., Campione, G., Minafò, G., Scibilia, N.: Compressive behaviour of laminated structural glass members. Eng. Struct. 33, 3402-3408 (2011)

Amadio, C., Bedon, C.: A buckling verification approach for monolithic and laminated glass elements under combined in-plane compression and bending. Eng. Struct. 52, 220229 (2013a)

Amadio, C., Bedon, C.: Corrigendum to "a buckling verification approach for monolithic and laminated glass elements under combined in-plane compression and bending". Eng. Struct. 57, 393 (2013b)

Belis, J., De Visscher, K., Callewaert, D., Van Impe, R.: Laminating metal-to-glass?: preliminary results of case-study. Glas. Perform. Days 2009, 191-193 (2009)

Belis, J., Mocibob, D., Luible, A., Vandebroek, M.: On the size and shape of initial out-of-plane curvatures in structural glass components. Constr. Build. Mater. 25, 2700-2712 (2011)

Carvalho, P., Cruz, P.J.S.: Connecting through reinforcementexperimental analysis of a glass connection using perforated steel plates. In: Challenging Glass 3. IOS Press, Delft (2012)

Carvalho, P., Cruz, P.J.S., Veer, F.: Perforated steel plate to laminated glass adhesive properties. Glas. Perform. Days 2011, 281-285 (2011) 
Cossavella, M., Panait, A.: Dimensionnement au déversement des raidisseurs et poutres en verre. Departement Enveloppe et Rêvetements (CSTB) (2008)

Denonville, J., Puller, K., Haase, W., Sobek, W.: Langzeittragverhalten von in Verbundglas integrierten Lasteinleitungselementen. In: Glasbau 2013. Ernst \& Sohn GmbH \& Co (2013)

DTA6/15-2253: SentryGlas de Kuraray Europe GmbHdocument Technique d 'Application (CSTB) (2015)

Feldmann, M., Langosch, K.: Knickfestigkeit und einheitliche Knickkurven für scheibenförmige Glasstützen mit Monoglasquerschnitt aus TVG und ESG. In: Glasbau 2010, pp. 70-80. Ernst \& Sohn GmbH \& Co (2010)

Foraboschi, P.: Buckling of a laminated glass column under test. Struct. Eng. 87, 20-26 (2009)

Galuppi, L., Royer-Carfagni, G.: Enhanced effective thickness of multi-layered laminated glass. Compos. Part B Eng. 64, 202-213 (2014)

Haldimann, M., Luible, A., Overend, M.: Structural use of glass. Int. Assoc. Bridge Struct. Eng. IABSE (2008)

Hanenberg, N.: Mechanical behaviour of laminated hybrid adhesive point connections when exposed to humidity conditions. Master Thesis. TU Delft (2016)

Lenk, P., Lancaster, F.: Connections in structural glass. Glass Perform. Days 2013, 380-384 (2013)

Louter, C.: Metal-to-glass bonding properties of an acrylate adhesive (DELO GB368) and an ionoplast interlayer (SentryGlas) at $23,-20$ and $6060^{\circ} \mathrm{C}$. Glass Perform. Days 2009, 139-143 (2009)

Louter, C., Belis, J., Bos, F.P., Callewaert, D., Veer, F.: Experimental investigation of the temperature effect on the structural response of SG-laminated reinforced glass beams. Eng. Struct. 32, 1590-1599 (2010)

Louter, C., Belis, J., Veer, F., Lebet, J.P.: Durability of SGlaminated reinforced glass beams: effects of temperature, thermal cycling, humidity and load-duration. Constr. Build. Mater. 27, 280-292 (2012a)

Louter, C., Belis, J., Veer, F., Lebet, J.P.: Structural response of SG-laminated reinforced glass beams; experimental investigations on the effects of glass type, reinforcement percentage and beam size. Eng. Struct. 36, 292-301 (2012b)

Luible, A.: Stabilité des éléments porteurs en verre. Thesis Dissertation. École Polytechnique Fédérale de Lausanne EPFL (2004)

Luible, A., Schärer, D.: Lateral torsional buckling of glass beams with continuous lateral support. Glass Struct. Eng. 1, 153171 (2016)

O'Callaghan, J.: An all glass cube in New York city. Glass Perform. Days 2007, 98-101 (2007)
O'Callaghan, J.: Adventures with structural glass. Glass Perform. Days 2012, 2-6 (2012)

Peters, S., Fuchs, A., Knippers, J., Behling, S., Bucak, Ö.: Ganzglastreppe mit transparenten SGP-klebeverbindungenKonstruktion und Statische Berechnung. Stahlbau 76, 151156 (2007)

Pilkey, W.D., Pilkey, D.F.: Peterson's Stress Concentration Factors. Wiley, New York (2008)

PrEN16612 (Draft): Glass in building — determination of the load resistance of glass panes by calculation and testing. CENEuropean Comitte For Standarization (2013)

Puller, K., Denonville, J., Sobek, W.: An innovative glass connection technique using an ionomer interlayer. Glass Perform. Days 15, 638-641 (2011)

Puller, K., Sobek, W.: Load-carrying behaviour of metal inserts embedded in laminated glass. In: Challenging Glass 3. IOS Press, Delft (2012)

Santarsiero, M.: Laminated connections for structural glass applications. Thesis Dissertation. École Polytechnique Fédérale de Lausanne-EPFL (2015)

Santarsiero, M., Louter, C.: Embedded and point laminated adhesive connections for glass structures?: parametric non-linear numerical investigations. Glass Perform. Days 2013, 265273 (2013)

Santarsiero, M., Louter, C.: Preliminary studies on the mechanical behaviour of thick embedded laminated connections. Glass Perform. Days 15, 10-18 (2015a)

Santarsiero, M., Louter, C.: Novel concept of performance enhancing hybrid adhesive connections in glass structures. Glass Perform. Days. 2015, 2-6 (2015)

Santarsiero, M., Louter, C.: Failure criteria for SentryGlas ionomer and TSSA silicon?: a theoretical introduction to a novel generalized triaxial model (GTM). Chall. Glass 1, 395 (2016)

Santarsiero, M., Louter, C.: Laminated connections for structural glass components?: a full-scale experimental study. Glass Struct. Eng. 2, 79-101 (2017)

Santarsiero, M., Louter, C., Nussbaumer, A.: The mechanical behaviour of SentryGlas ionomer and TSSA silicon bulk materials at different temperatures and strain rates under uniaxial tensile stress state. Glass Struct. Eng. 1, 395-415 (2016a)

Santarsiero, M., Louter, C., Nussbaumer, A.: Laminated connections for structural glass applications under shear loading at different temperatures and strain rates. Constr. Build. Mater. 128, 214-237 (2016b) 